\title{
Routine Use of Gastrograffin Enema prior to the Reversal of a Loop Ileostomy
}

\author{
G. Khair \\ O. Alhamarneh \\ J. Avery J. Cast J.Gunn \\ J.R.T. Monson \\ J. Hartley
}

Academic Surgical Unit, Castle Hill Hospital, Cottingham, Hull, UK

\section{Key Words}

Gastrograffin enema · Anastomotic leak · Loop ileostomy · Anterior resection

\begin{abstract}
Background/Aims: Anastomotic failure occurs in up to $10 \%$ of patients following anterior resection. Selective use of a loop ileostomy may reduce the septic consequences of anastomotic leak. The use of gastrograffin enema to confirm the anastomotic integrity prior to ileostomy closure is still controversial. Our aim was to determine the impact of the routine use of gastrograffin enema on patients' management prior to ileostomy reversal. Methods: A review of 81 patients who underwent low anterior resection with loop ileostomy for rectal cancer over 3 years. Results: Gastrograffin enema was performed in 69 patients (85.2\%). The mean time from operation to gastrograffin enema was 22 weeks. Four patients (5.8\%) had a positive radiological leak without clinical suspicion of anastomotic problems, 2 patients (2.9\%) of these subsequently had the ileostomy closed despite the positive result, 2 patients (2.9\%) had a gastrograffin enema repeated which showed no leak and the patients are awaiting reversal. Conclusion: The incidence of positive radiological leak in uncomplicated patients is low; such patients had their loop ileostomies closed with or without serial gastrograffin enema. Routine gastrograffin enema in the absence of a clinical suspicion of anastomotic failure would appear to be of little value.

Copyright $\odot 2007$ S. Karger AG, Basel
\end{abstract}

\section{Introduction}

Anterior resection is the operation of choice for low rectal cancer, the formation of a straight anastomosis or colopouch anal anastomosis with total mesorectal excision is regarded the procedure of choice for such lesions $[1,2]$. Mesorectal excision allows sphincter preservation without compromising local recurrence and survival rates $[3,4]$. However, the major complication of mesorectal excision is a significant anastomotic leak rate $[5,6]$. Anastomotic leak is a recognized complication of anterior resection with published rates varying between 2.8 and $25 \%[7,8]$. The septic consequences of anastomotic failure are associated with significant mortality and morbidity rates [9], with reported mortality rates varying between 6 and 22\% [10]. In addition, it has been shown that anastomotic failure increases the recurrence rates and decreases tumour-free survival rates [11-13].

A defunctioning proximal stoma is commonly fashioned in order to mitigate against the septic consequences of anastomotic failure. However, its formation is still controversial, so that some studies have suggested that the use of covering stomas does not reduce anastomotic leak complications $[14,15]$. In addition, subsequent stoma reversal involves additional hospital admissions and operative risks and complications of having the stoma closed $[16,17]$. Others have proved that its use has reduced surgical intervention after anastomotic leak has developed [18, 19].

Covering stomas are routinely closed at 8-12 weeks after the initial surgery. Before stoma closure, it is com-

G. Khair

Academic Surgical Unit, Castle Hill Hospital

Cottingham Hull HU16 5JQ (UK)

Tel. +44 1482623 225, Fax +44 1482623 274, E-Mail g.khair@hull.ac.uk
Fax +4161306 1234 E-Mail karger@karger.ch www.karger.com (c) 2007 S. Karger AG, Basel
$0253-4886 / 07 / 0245-0338 \$ 23.50 / 0$

Accessible online at:

www.karger.com/dsu 


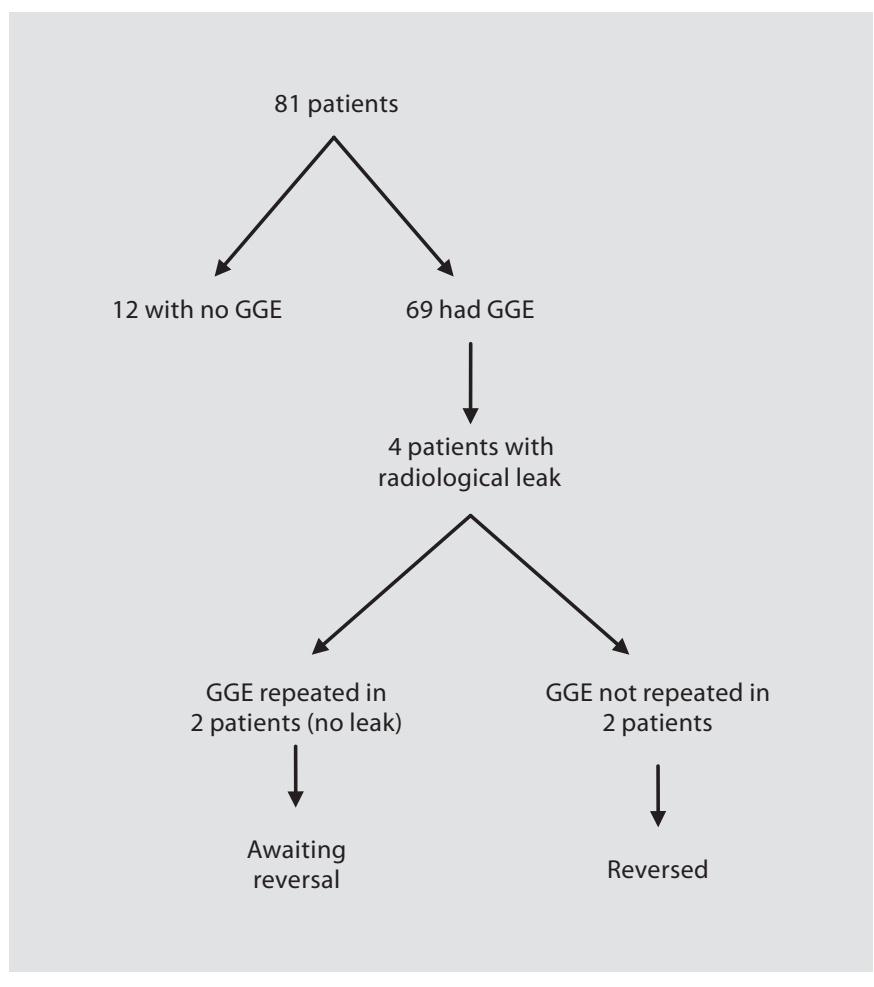

Fig. 1. Summary of results. GGE = Gastrograffin enema.

mon practice to check the integrity of the anastomosis by performing a water-soluble contrast enema to rule out anastomotic leak or fistula formation. However, it is unclear whether this should be performed selectively or routinely. In addition the management of radiological leakage is controversial without a good evidence base. The aim of this study was to determine the routine use of gastrograffin enema prior to ileostomy reversal on patients' management.

\section{Methods and Materials}

This is a retrospective review of patients with low rectal cancer who underwent a low anterior resection with a covering loop ileostomy over a period of 3 years.

A routine double-contrast gastrograffin enema was performed prior to stoma reversal in order to check the anastomosis. The procedure was performed by a radiologist or a radiographer under fluoroscopic guidance, patients were put on a table in the left lateral position, a Foley catheter size $12-16 \mathrm{~F}$ was introduced per anum without inflating the balloon and a sufficient amount of gastrograffin contrast was introduced slowly to distend and highlight the anastomosis and the proximal bowel, two or more images were taken. All radiological images were reviewed by a senior radiologist.
We obtained follow-up information from patients' medical notes and gastrograffin enema radiology reports and identified the patients with asymptomatic radiological leak in order to determine the impact of such a positive result on patients' management.

\section{Results}

There were 81 patients recruited in this retrospective study; 52 males (64.2\%) and 29 females (35.8\%). Patients' age ranged between 48 and 90 years with a median of 70.0 years.

The postoperative histology revealed 18 cases $(22.2 \%)$ with Dukes' A, 25 (30.9\%) Dukes' B, 36 (44.4\%) Dukes' C and 2 cases $(2.5 \%)$ Dukes' D.

Three of 81 patients developed clinical signs of anastomotic failure for a clinical leak rate of $3.7 \%$. These were confirmed radiologically, 1 patient was treated by radiological drainage but 2 patients required laparotomy and 1 died.

The 30 -day mortality rate in this series was $4.9 \%$ were 4 patients died in the postoperative period as a result of pulmonary embolism, multi-organ failure secondary to acute liver failure, intra-abdominal sepsis secondary to anastomotic failure and postoperative pneumonia.

The mean time from the initial operation to gastrograffin enema was 22 weeks ranging from 1 to 56 weeks.

$69(85.2 \%)$ patients had a gastrograffin enema prior to loop ileostomy reversal to asses the integrity of the anastomosis, 4 (5.8\%) of whom showed minor anastomotic leak on their gastrograffin enema but none of them had clinical signs or symptoms suggestive of clinical anastomotic failure. Two patients of these (2.9\%) were reversed without repeating the gastrograffin enema 4 and 5 months later, and $2(2.9 \%)$ had a serial of gastrograffin enema, which came back as normal, and the patients are waiting for their loop ileostomy to be reversed. Figure 1 summarizes the above results.

12 patients (14.8\%) of the total number of patients did not have a gastrograffin enema before the loop ileostomy closure, instead these patients underwent a specific examination under anesthesia with sigmoidoscopy as the final assessment of their anastomosis; none of them had signs or symptoms suggestive of clinical leak and none of these patients had postoperative complications after the loop ileostomy closure.

$11(13.6 \%)$ of the 81 patients didn't have their stoma closed. The causes of not reversing those stomas are shown in table 1 . 


\section{Discussion}

Anterior resection with a formation of a covering loop ileostomy is the routine operation for patients with low rectal cancer in our unit; a loop ileostomy is fashioned traditionally to reduce the septic consequences of anastomotic failure. A gastrograffin enema is done prior to ileostomy reversal in order to check the integrity of anastomosis and to rule out any leak, blockage or fistula formation $[20,21]$.

A routine gastrograffin enema is not performed routinely in our unit in the immediate post-operative period unless there is a clinical suspicion of anastomotic leak, as it has been shown that the use of gastrograffin enema in the immediate postoperative period has a low predictive value in detecting sub-clinical leaks and might risk interrupting an intact anastomosis by the pressure produced when installing the contrast [22].

Another disadvantage of having a gastrograffin enema done in the postoperative period is that if there is an underlying sepsis, infection may spread through excessive air insufflation during the procedure leading to haematogenous infection [23].

Gastrograffin enema would have routinely been done at 6-8 weeks postoperatively but in our study the mean time from the initial operation to gastrograffin enema was 22 weeks. The reason for this was that some patients had their surgery postponed for various reasons, hence the delay in performing gastrograffin enema.

The radiological leak rate in our study has shown to be low where only 4 (5.9\%) of the 69 patients who had gastrograffin enema prior to stoma reversal had a positive radiological leak, our results were in accordance to other results in the literature where one study showed that the leak rate on gastrograffin enema 6 weeks postoperatively was $1.7 \%$ where only 1 patient had radiological leak of 47 patients who underwent low anterior resection and loop ileostomy formation for rectal cancer [24]. Another two studies showed no radiological leak on all patients who underwent anterior resection and defunctioning stoma formation $[25,26]$.

Tong et al. [27] tried to find an alternative for gastrograffin enema to check the integrity of the anastomosis. They performed a prospective study on 129 patients who underwent colo-anal or colo-rectal anastomosis or ileopouch anal anastomosis with a diverting stoma, and anastomotic integrity was checked 3-6 weeks postoperatively by digital rectal examination followed by a watersoluble contrast enema. Anastomotic defects on digital examination and leaks were studied. Their results showed
Table 1. Reason for not reversing stoma

\begin{tabular}{|c|c|}
\hline $\begin{array}{l}\text { Patient } \\
\text { No. }\end{array}$ & Reason for not reversing loop ileostomy \\
\hline 1 & Had positive radiological leak, awaiting reversal \\
\hline 2 & Developed anastomotic stricture \\
\hline 3 & Died of PE in the post-operative period \\
\hline 4 & Died of multi-organ failure post-operatively \\
\hline 5 & Having radiotherapy \\
\hline 6 & Had clinical leak post-operatively and on chemotherapy \\
\hline 7 & Developed wound dehiscence and anastomotic stricture \\
\hline 8 & Died of intra-abdominal sepsis post operatively \\
\hline 9 & $\begin{array}{l}\text { Developed recurrent episodes of cholangiitis post- } \\
\text { chemotherapy }\end{array}$ \\
\hline 10 & $\begin{array}{l}\text { Had further resection (abdominoperineal excision of } \\
\text { the rectum) }\end{array}$ \\
\hline 11 & On chemotherapy awaiting reversal \\
\hline
\end{tabular}

that water-soluble contrast enema has a false-positive rate of $6.4 \%$ with 13 patients with normal digital examination having positive radiological leak. These patients had their stomas reversed with no subsequent complications. Also the study showed that water-soluble contrast enema had a false-negative rate of $3.5 \%$ where 7 patients had big defects on rectal examinations but they had normal enema study; these patients stoma closure was delayed to prevent pelvic sepsis. Tong et al. concluded in this study that digital rectal examination in the use of an experienced surgeon yields more useful clinical information than the enema study.

In our study, 4 patients had a positive radiological leak; 2 of them had their stoma reversed despite the fact that they had a positive leak on the enema images; both of these patients had no subsequent complications. This fact proves that routine gastrograffin in the absence of a clinical suspicion of anastomotic failure would appear to be of little value.

\section{Conclusion}

The fact that the incidence of positive anastomotic leak on gastrograffin enema in patients with an uncomplicated post-operative course is low should make us consider abandoning the routine use of gastrograffin enema before stoma closure, and a gastrograffin enema should be only used selectively to confirm a clinical suspicion of anastomotic leak. 


\section{References}

1 MacFarlane JK, Ryall RD, Heald RJ: Mesorectal excision for rectal cancer. Lancet 1993; 341:457-460.

$\checkmark 2$ Williams N, Seow-Choen F: Physiological and functional outcome following ultra-low anterior resection with colon pouch-anal anastomosis. Br J Surg 1998;85:1029-1035.

$\checkmark 3$ Heald RJ, Karanjia ND: Results of radical surgery for rectal cancer. World J Surg 1992; 16:848-857.

4 Kirwan WO, O’Riordain MG, Waldron R: Declining indications for abdominoperineal resection. Br J Surg 1989;76:1061-1063.

$\checkmark 5$ Karanjia ND, Corder AP, Bearn P, Heald RJ: Leakage from stapled low anastomosis after total mesorectal excision for carcinoma of the rectum. Br J Surg 1994;81:1224-1226.

-6 Arbman G, Nilsson E, Hallbook O, Sjodahl $\mathrm{R}$ : Local recurrence following total mesorectal excision for rectal cancer. Br J Surg 1996; 83:375-379.

7 Horgan AF, Finlay IG: Preoperative staging of rectal cancer allows selection of patients for preoperative radiotherapy. Br J Surg 2000;87:575-579.

8 Wheeler JM, Gilbert JM: Controlled intraoperative water testing of left-sided colorectal anastomoses: are ileostomies avoidable? Ann R Coll Surg Engl 1999;81:105-108.

$>9$ Goligher JC, Graham NG, De Dombal FT: Anastomotic dehiscence after anterior resection of rectum and sigmoid. Br J Surg 1970;57:109-118.

10 Ajani JA: In rectal carcinoma, colostomy or no colostomy: is this the question? J Clin Oncol 1993;11:193-194.

- 11 Akyol AM, McGregor JR, Galloway DJ, Murray $\mathrm{GD}$, George WD: Anastomotic leaks in colorectal cancer surgery: a risk factor for recurrence? Int J Colorectal Dis 1991;6:179183.
12 Fujita S, Teramoto T, Watanabe M, Kodaira S, Kitajima M: Anastomotic leakage after colorectal cancer surgery: a risk factor for recurrence and poor prognosis. Jpn J Clin Oncol 1993;23:299-302.

13 Petersen S, Freitag M, Hellmich G, Ludwig $\mathrm{K}$ : Anastomotic leakage: impact on local recurrence and survival in surgery of colorectal cancer. Int J Colorectal Dis 1998;13:160163.

14 Mealy K, Burke P, Hyland J: Anterior resection without a defunctioning colostomy: questions of safety. Br J Surg 1992;79:305307.

$>15$ Fielding LP, Stewart-Brown S, Hittinger R, Blesovsky L: Covering stoma for elective anterior resection of the rectum: an outmoded operation? Am J Surg 1984;147:524-530.

16 O'Leary DP, Fide CJ, Foy C, Lucarotti ME: Quality of life after low anterior resection with total mesorectal excision and temporary loop ileostomy for rectal carcinoma. $\mathrm{Br}$ J Surg 2001;88:1216-1220.

$>17$ Camilleri-Brennan J, Steele RJ: Prospective analysis of quality of life after reversal of a defunctioning loop ileostomy. Colorectal Dis 2002;4:167-171.

$>18$ Marusch F, Koch A, Schmidt U, Geibetaler S, Dralle H, Saeger HD, Wolff S, Nestler G, Pross M, Gastinger I, Lippert H: Value of a protective stoma in low anterior resections for rectal cancer. Dis Colon Rectum 2002;45: 1164-1171.

19 Gastinger I, Marusch F, Steinert R, Wolff S, Koeckerling F, Lippert H: Protective defunctioning stoma in low anterior resection for rectal carcinoma. Br J Surg 2005;92:11371142 .
20 Shorthouse AJ, Bartram CI, Eyers AA, Thomson JP: The water soluble contrast enema after rectal anastomosis. Br J Surg 1982; 69:714-717

>21 Civelli EM, Gallino G, Valvo F, Cozzi G, Belli F, Bonfanti G, Folini C, Suman L, Meroni R, Vercelli R, Leo E, Severini A: Correlation between radiotherapy and suture fistulas following colo-anal anastomosis for carcinoma of the rectum evaluation of 152 consecutive patients. Tumori 2002;88:321-324.

22 Akyol AM, McGregor JR, Galloway DJ, George WD: Early postoperative contrast radiology in the assessment of colorectal anastomotic integrity. Int J Colorectal Dis 1992; 7:141-143.

23 Cappell MS, Ghandi D, Huh C: A study of the safety and clinical efficacy of flexible sigmoidoscopy and colonoscopy after recent colonic surgery in 52 patients. Am J Gastroenterol 1995;90:1130-1134.

24 Elahi MM: Water soluble contrast enema in detecting true sub-clinical anastomotic leak: when to perform. J Radiol 2002 (May).

25 MacLeod I, Watson AJM, J. H, Hussey JK, O'Kelly TJ: Colonic pouchography is not routinely required prior to stoma closure. Colorectal Dis 2004;6:162-164.

26 Kalady M, Fields R, Wilkins K, Onaitis M, Tyler D, Mantyh C, Ludwig K, Durham NC: Routine contrast imaging of low pelvic anastomosis before temporary stoma closure: lack of clinical impact on the patient management. American Gastroenterology Association 2002.

$>27$ Tang CL, Seow-Choen F: Digital rectal examination compares favourably with conventional water-soluble contrast enema in the assessment of anastomotic healing after low rectal excision: a cohort study. Int J Colorectal Dis 2005;20:262-266. 